\title{
How did a prosthetic femoral head migrate to the mesorectum?
}

\author{
Matthew Howell, Graeme Smith, Andrew G Marsh
}

Queen Elizabeth University Hospital, NHS Greater Glasgow and Clyde, Glasgow, UK

Correspondence to Mr Matthew Howell, m.howell@doctors.org.uk

Accepted 17 July 2018

\section{DESCRIPTION}

This 64-year-old man underwent a total hip replacement for osteoarthritis via a posterior approach. Day 1 postoperatively, he felt his hip click while turning into a chair. X-ray revealed an anterior hip dislocation with the prosthetic femoral head disengaged and migrated into the pelvis. CT demonstrated the ceramic head was retroperitoneal, anterior to the right iliac bone within the iliopsoas muscle interval (figure 1). His case was discussed with hip revision and trauma specialists with a provisional plan to revise the hip replacement and remove the femoral head. The patient, however, did not wish invasive, intra-abdominal surgery and requested a limited approach for implant retrieval. Revision hip surgery was performed with anteversion of the acetabular component adjusted; retrieval of the femoral head was not possible through this approach. A further attempt via a minimally invasive, retroperitoneal approach along the inner table of pelvic wall was used but was also unsuccessful.

Following revision surgery, he initially made a good recovery and was discharged home. At 2-week follow-up, however, he had developed some groin pain. A repeat X-ray and CT scan showed the implant had migrated deeper into the pelvic cavity, inferior to the iliac vessels and indenting onto the mesorectum (figure 2). Removal of the femoral head was advised and performed laparoscopically. The right side of the mesorectum was mobilised to the pelvic floor, and the implant was successfully retrieved with an open grasper inside the taper with counter pressure applied per rectum. The patient made a good recovery. At latest follow-up, 6 months postretrieval, his groin pain had resolved, he walks unaided and has resumed hill walking.

Dislocation of total hip replacement is a known complication; however, component disassociation in this context is rare. Cases have been reported; however, in all documented cases, it has occurred
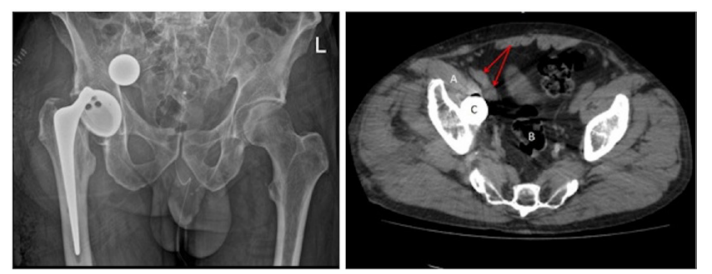

Figure 1 X-ray and CT at time of dislocation. The detached femoral head (C) component has migrated superomedially lies within the right iliopsoas muscle (A). ((B) Rectum; red arrows, right external iliac artery and vein).
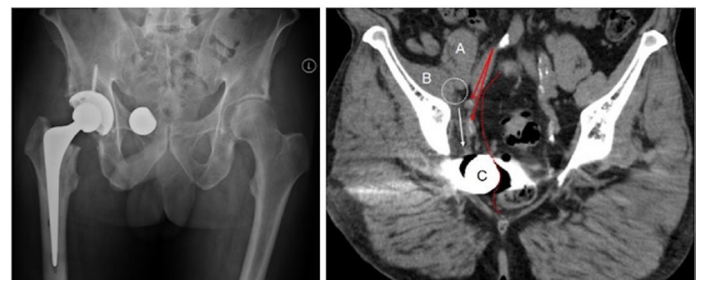

Figure 2 Follow-up X-ray and CT. The detached component $(C)$ has continued its migration inferiorly alongside the pelvis side wall (solid white arrow) and deep to the internal iliac vessels (solid red arrows). It has come to lie deep in the pelvis indenting the mesorectum (dashed red line).

intraoperatively with trial components. ${ }^{1-5}$ In our case, it is unclear why the definitive components disengaged during dislocation. The femoral head was impacted during surgery. Anterior dislocation likely occurred during external rotation of the hip. We believe that subsequent internal rotation probably occurred as the hip attempted to relocate, resulting in impaction of the femoral head against the acetabular component rim and disengagement. Other risk factors for component separation, including obesity and reduced head-neck ratio, ${ }^{1}$ were not applicable to this case (body mass index 26, standard offset prosthetic head).

Previous reports suggest that removal of plastic trial implants is not mandatory if asymptomatic ${ }^{23}$ and that further migration is uncommon. ${ }^{2}$ In our case, however, further migration of the femoral head did occur towards the mesorectum. This resulted in concerns of theoretical risk of erosion into the gastrointestinal tract. ${ }^{6}$ In light of this case, we suggest that early removal of a disengaged femoral head is performed. Different approaches have been described for this, including retroperitoneal approaches or via laparotomy. ${ }^{23}$ Our case highlights that a laparoscopic approach can also be used.

\section{Learning points}

Early removal is recommended as implants can migrate within the pelvis and risk gastrointestinal complications.

- A laparoscopic approach should be considered for retrieval.

Contributors $\mathrm{MH}$, orthopaedic registrar, was involved in patient care and primary author of the article. GS, colorectal consultant, performed laparoscopic procedure and developed images for the 
article. AM, orthopaedic consultant, oversaw clinical care of the patient and write up of the article.

Funding The authors have not declared a specific grant for this research from any funding agency in the public, commercial or not-for-profit sectors.

Competing interests None declared.

Patient consent Obtained.

Provenance and peer review Not commissioned; externally peer reviewed.

\section{REFERENCES}

1 Siddiqi A, Talmo CT, Bono JV. Intraoperative femoral head dislodgement during total hip arthroplasty: a report of four cases. Arthroplast Today 2018:4:44-50.
2 Vertelis A, Vertelis L, Tarasevicius S. Trial femoral head loss in to the soft tissues of pelvis during primary total hip replacement: a case report. Cases J 2008;1:151.

3 Callaghan JJ, McAndrew C, Boese CK, et al. Intrapelvic migration of the trial femoral head during total hip arthroplasty: is retrieval necessary? A report of four cases. lowa Orthop J 2006;26:60-2.

4 Citak M, Klatte TO, Zahar A, et al. Intrapelvic dislocation of a femoral trial head during primary total hip arthroplasty requiring laparotomy for retrieval. Open Orthop J 2013:7:169-71.

5 Batouk O, Gilbart M, Jain R. Intraoperative dislocation of the trial femoral head into the pelvis during total hip arthroplasty: a case report. J Bone Joint Surg Am 2001;83A:1549-51.

6 Alfonso D, Idjadi J, Lamont JG. Retrieval of a trial femoral head that displaces into the periacetabular soft tissue during mini-incision total hip arthroplasty. A case report. J Bone Joint Surg Am 2006;88:866-8.

Copyright 2018 BMJ Publishing Group. All rights reserved. For permission to reuse any of this content visit http://group.bmj.com/group/rights-licensing/permissions.

BMJ Case Report Fellows may re-use this article for personal use and teaching without any further permission.

Become a Fellow of BMJ Case Reports today and you can:

- Submit as many cases as you like

- Enjoy fast sympathetic peer review and rapid publication of accepted articles

- Access all the published articles

Re-use any of the published material for personal use and teaching without further permission

For information on Institutional Fellowships contact consortiasales@bmjgroup.com

Visit casereports.bmj.com for more articles like this and to become a Fellow 